\title{
Improving the carbon dioxide uptake efficiency of activated carbons using a secondary activation with potassium hydroxide
}

\author{
Michal Zgrzebnicki, Ewa Michalczyszyn, Rafal J. Wrobel \\ West Pomeranian University of Technology, Szczecin, Institute of Chemical and Environment Engineering, ul. Pulaskiego 10, \\ 70-322 Szczecin, Poland \\ "Corresponding author: e-mail: Rafal.Wrobel@zut.edu.pl
}

\begin{abstract}
Secondary activation of commercial activated carbon (AC) ORGANOSORB 10-CO was carried out at 600, 700 and $800^{\circ} \mathrm{C}$ with mass ratios of potassium to $\mathrm{AC}(\mathrm{K} / \mathrm{AC})$ in range 1-3. Crucial samples have shown following $\mathrm{CO}_{2}$ uptakes and SSA - $3.90 \mathrm{mmol} / \mathrm{g}$ and $1225 \mathrm{~m}^{2} / \mathrm{g}, 4.54 \mathrm{mmol} / \mathrm{g}$ and $1546 \mathrm{~m}^{2} / \mathrm{g}, 4.28$ and $1717 \mathrm{~m}^{2} / \mathrm{g}$ for pristine material and samples obtained at $700^{\circ} \mathrm{C}$ with $\mathrm{K} / \mathrm{AC}=2$ and at $800^{\circ} \mathrm{C}$ with $\mathrm{K} / \mathrm{AC}=3$ respectively. Last sample also indicated significant mesopore volume increase in diameter range $2-5 \mathrm{~nm}$, from 0.11 to $0.24 \mathrm{~cm}^{3} / \mathrm{g}$. $\mathrm{CO}_{2}$ uptake increase was explained by formation of micropores up to diameter of $0.8 \mathrm{~nm}$, which distribution was established from $\mathrm{CO}_{2}$ sorption using DFT. Surface chemistry of all samples has not changed during modification, what was proven by XPS. Moreover, deeper incorporation of potassium ions into graphite at higher temperatures was observed as confirmed with EDS, XPS and XRD.
\end{abstract}

Keywords: activated carbon, activation, pore size distribution, DFT.

\section{INTRODUCTION}

According to NASA data, average global temperature is steadily increasing ${ }^{1}$, resulting in 2017 with the highest change of temperature relative to 1951-1980 average temperatures. The full consequences of such an increase are unknown to mankind and one can only speculate on possible outcomes of global warming. The most obvious scenario is a rise in sea level by $0.8 \mathrm{~m}$ by the end of the century $^{2}$, due to melting of glaciers. The phenomenon of increasing temperature is attributed to intensifying greenhouse effect. The greenhouse effect is a blockage of secondary radiation emitted by the Earth's surface after absorption of primary solar radiation. This mechanism results in the accumulation of excessive energy, which makes the Earth's surface warmer - compared to a case without greenhouse gases in the atmosphere ${ }^{3}$. Outgoing radiation is absorbed by so called greenhouse gases, like methane, water vapor and carbon dioxide. It was proven that the concentration of $\mathrm{CO}_{2}$ has increased in the atmosphere by over $120 \mathrm{ppm}$ since the industrial revolution. The preindustrial level used to be $280 \mathrm{ppm}^{4}$ and in May 2018 the $\mathrm{CO}_{2}$ concentration was $404 \mathrm{ppm}^{5}$. Emissions of $\mathrm{CH}_{4}$ and $\mathrm{H}_{2} \mathrm{O}_{(\mathrm{g})}$ are virtually impossible to control. On the other hand, $\mathrm{CO}_{2}$ emission could be divided on two sources - natural and anthropogenic. The second one can be in some way controlled, due to its origin from industry, chemical processes and burning of fossil fuels. Therefore, there has been interest in comprehensive research to reduce carbon dioxide emission to the atmosphere, to abate further climate changes. The extensive discussion about anthropogenic $\mathrm{CO}_{2}$ impact both positive and negative is discussed elsewhere ${ }^{6}$.

One of the leading ideas of reducing $\mathrm{CO}_{2}$ emission is Carbon Capture and Storage (CCS). CCS techniques today are mainly focused on separation of carbon dioxide from flue gases and its storage e.g. underground in geological formations. CCS may significantly contribute to lowering the $\mathrm{CO}_{2}$ levels and thus alleviate climate change.

One of the methods of carbon dioxide separation is a post-combustion method ${ }^{7}$, which is crucial for many countries using fossil fuels to generate electric energy.
Complete combustion of carbonaceous materials in conventional power plants produces a limited number of products, mainly $\mathrm{CO}_{2}$ and $\mathrm{H}_{2} \mathrm{O}_{(\mathrm{g})}$ diluted in nitrogen which is the main constituent of flue gases. Carbon dioxide can be separated from the exhaust or residual gas and after water removal prepared for its storage or usage. The advantage of post-combustion method is its relatively low cost of implementation in already existing installations and low complexity compared to building new facilities or inventing new technologies. On the other hand the operational costs may be higher compared to facilities designed from scratch for CCS.

The CCS technology requires appropriate $\mathrm{CO}_{2}$ sorbents. The most promising materials for post-combustion removal of $\mathrm{CO}_{2}$ are solid adsorbents, like activated carbons ${ }^{8-10}$ or titani $\mathrm{a}^{21-14}$, rather than liquid absorbents like amines, due to required lower energy of regeneration, higher stability and noncorrosive properties.

Activated carbon $(\mathrm{AC})^{\mathbf{1 5}, \mathbf{1 6}}$ is a porous material with high specific surface area (SSA), significant pore volume and good thermal and chemical stability. This particular adsorbent is most often obtained by thermal treatment of carbonaceous material, for instance $\operatorname{wood}^{17}$, cherry stones $^{18}$, charcoal ${ }^{19}$ and leafs ${ }^{20}$, followed by activation, which could be physical ${ }^{21}$, chemical ${ }^{22,23}$ or combined ${ }^{24}$. There are other more exotic and usually more expensive sources of carbonaceous materials. For example one may obtain extremely pure and well defined carbonaceous materials by decomposition of polymers ${ }^{25}$. The catalytic decomposition of hydrocarbons over catalyst like iron leads to formation of carbon nanotubes or carbon deposits of various morphologies and properties ${ }^{26,27}$.

Depending on properties of ACs there are many applications they are suitable for, like material for lithium-ion batteries $^{28}$, catalysis ${ }^{29,30}$ water and gas purification ${ }^{31}$ and many others.

The properties of the activated carbon may be tailored for particular application. The surface chemistry may be appropriately modified to adsorb desired molecules. Moreover, the content of inorganic impurities may vary due to origin of carbonaceous materials, and has 
an impact on the AC's properties ${ }^{6}$. This is the reason why researchers investigate so-called model systems like carbon nanotubes, which do not have mineral content and thus the impact of modifications on properties is considerably easier to understand ${ }^{\mathbf{3 2}}$. However, even for model carbonaceous systems the understanding of undergoing phenomena during sorption of gases is not complete, due to their complexity. In this paper the activation process of carbon with $\mathrm{KOH}$ is investigated to find the relations between process parameters and resulting AC's structure.

Activation process with $\mathrm{KOH}$ has been described very well in scientific literature ${ }^{\mathbf{2 0}, 23,33,34}$. Nevertheless, most of the authors rarely provide results of activation with more than one variable, for instance changing only $\mathrm{KOH} /$ carbon ratio $^{23}$ or changing only the temperature ${ }^{22}$. Tiwari et. $\mathrm{al}^{\mathbf{3 3}}$ performed experiments with different $\mathrm{KOH}$ loading at the same temperature and one particular ratio at extra three different temperatures. However, micropore size distribution was not calculated, which is crucial for sorption of $\mathrm{CO}_{2}$. Presser et. $\mathrm{al}^{35}$ confirmed that pores up to $0.5 \mathrm{~nm}$ and $0.8 \mathrm{~nm}$ in diameter are crucial for carbon dioxide uptake at 0.1 and 1 bar respectively. Moreover, already activated material can be further activated to develop new porous structure, depending on $\mathrm{KOH} /$ carbon ratio, temperature and time of activation. Calculating pore size distributions allows to determine what pores are being created in specific conditions, thus it give an opportunity to obtain desired material for particular application.

The goal of this research is an extension of general knowledge about carbon activation with potassium hydroxide and the related micropore distributions - by presenting results of secondary activation of commercial $\mathrm{AC}$ with different $\mathrm{KOH}$ loadings at different temperatures. The additional goal is recipe for enhancement of commercially available ACs toward better $\mathrm{CO}_{2}$ uptake under ambient temperature and pressure. Therefore, the samples after secondary activation were thoroughly characterized and tested with respect to $\mathrm{CO}_{2}$ uptake.

\section{EXPERIMENTAL}

\section{Material and methods}

Activated carbon ORGANOSORB 10-CO (AC) was obtained from company DESOTEC (Roeselare, Belgium). Potassium hydroxide (reagent grade, CHEMPUR) and hydrochloric acid (35-38\% p.a., CHEMPUR) were used for the activation. 5.0 nitrogen was used as the inert atmosphere for the activation process and for BET measurements. In case of carbon dioxide uptake measurements, the gas purity was 4.5.

\section{Additional activation of AC}

This paper provides results of activation with mass ratios of potassium to $\mathrm{AC}(\mathrm{K} / \mathrm{AC})$ equal to $1: 1,2: 1$, $3: 1$. The commercial AC was thoroughly characterized elsewhere ${ }^{6}$. Commercial material was washed with solution of hydrochloric acid to remove already present potassium and washed with distilled water up to $\mathrm{pH} \sim 7$. Such material will be further referred as 10CO_pristine.

Commercial AC was activated in following manner:
The appropriate mass of $\mathrm{KOH}$ was dissolved in $20 \mathrm{ml}$ of deionized water. The AC was added to the solution, stirred for 30 minutes and placed in drying oven at $100^{\circ} \mathrm{C}$ overnight to evaporate the water. Each of the $\mathrm{K} / \mathrm{AC}$ ratio was activated at temperatures of 600,700 and $800^{\circ} \mathrm{C}$ for 2 hours under $100 \mathrm{ml} / \mathrm{min}$ flow of nitrogen. After activation each sample was washed with hydrochloric acid to remove any residual potassium from the material followed by washing with water up to $\sim 7 \mathrm{pH}$. The materials obtained during additional activation process with $\mathrm{KOH}$ will be further referred as $10 \mathrm{CO}$ _X_Z, where $\mathrm{X}$ stands for temperature of activation and $\bar{Z}$ stands for $\mathrm{K} / \mathrm{AC}$ mass ratio.

\section{Characterization methods}

Nitrogen adsorption-desorption isotherms at $-196^{\circ} \mathrm{C}$ and relative pressure up to 0.99 were measured (Quantachrome; Autosorb Instrument). Those isotherms were used for the calculation of specific surface area (SSA) using Brunauer-Emmett-Teller (BET) equation. Density functional theory (DFT) was used to determine pore size distributions (PSD) from - adsorption-desorption isotherms of nitrogen at $-196^{\circ} \mathrm{C}$ and carbon dioxide at $0^{\circ} \mathrm{C}$. The pore size measurement ranges were $1.2-2.0$ $\mathrm{nm}$ and $0.3-1.2 \mathrm{~nm}$ for PSD of micropores and submicropores respectively. Please note that later in the paper as a volume of submicropores $\left(\mathrm{V}_{\text {submicro }}\right)$ will be given the narrower range i.e. $0.3-0.8 \mathrm{~nm}$, because it is well established in literature that pores up to $0.8 \mathrm{~nm}$ are crucial for carbon dioxide adsorption for pressures up to $1 \mathrm{bar}^{35}$, and one of the goals of this paper is a preparation of $\mathrm{CO}_{2}$ sorbents with good performance under ambient pressure, i.e. up to 1 bar.

Scanning electron microscopy (SEM) (SU8020; Hitachi) with energy dispersive X-ray spectrometer (EDS) analysis was used to determine morphology and elemental composition of selected samples.

The X-ray photoelectron spectroscopy measurements were performed in a commercial multipurpose (XPS, LEED, UPS, AES) UHV surface analysis system (PRE$V A C$ ), which is operating at a base pressure in the low $10^{-10}$ mbar range. The UHV system consist of two main chambers. The preparation chamber gives the possibility of cleaning and control of the surface composition by Auger spectroscopy (AES) and low-energy electron diffraction (LEED). The analysis chamber is equipped with nonmonochromatic X-ray photoelectron spectroscopy (XPS) and kinetic electron energy analyzer (SES 2002; Scienta). The calibration of spectrometer was performed using $\mathrm{Ag} 3 \mathrm{~d}_{5 / 2}$ transition. The sample in the form of fine powder was thoroughly degassed prior measurement so that during XPS measurements the vacuum was in the low $10^{-9}$ mbar range. The X-ray photoelectron spectroscopy was performed using $\mathrm{Al} \mathrm{K}_{\alpha}(\mathrm{h} v=1486.6 \mathrm{eV})$ radiation. The measurements were performed for binding energies corresponding to $\mathrm{O} 1 \mathrm{~s}, \mathrm{C} 1 \mathrm{~s}$ and $\mathrm{K} 2 \mathrm{p}$ regions. CasaXPS version 2.3.16Dev39 was used for evaluation of results. Possible charging effects were calibrated with respect to the C1s signal - which is commonly used as it is on the surface of investigated materials as impurity ${ }^{\mathbf{3 6}}$.

X-ray diffraction patterns of AC's were acquired by using an Empyrean diffractometer (PANalytical), equipped with a wide angle detector (PIXcel) and a monochroma- 
tor which greatly lowered the signal to noise ratio. Data were collected over a $2 \theta$ range of $10 \div 60^{\circ}$ using copper radiation $(\lambda \mathrm{K} \alpha 1=0.154056 \mathrm{~nm})$.

\section{RESULTS AND DISCUSSION}

\section{Textural characterization}

All of obtained samples were characterized in terms of textural properties, like SSA and PSDs of meso- and micropores via nitrogen sorption. Moreover submicropore volume and distribution was determined via $\mathrm{CO}_{2}$ sorption. Table 1 presents results of those analyses. Please note that submicropore volume is not included in total pore volume. Pore volumes were presented for pores with diameters in the range of 1.2-200 nm (total), 1.2-2.0 $\mathrm{nm}$ (micro) and $0.3-0.8 \mathrm{~nm}$ (submicro). at temperatures 600 and $700^{\circ} \mathrm{C}$. In case of activation at $800^{\circ} \mathrm{C}$ the submicropore volumes are comparable.

Isotherms of nitrogen adsorption/desorption at $-196^{\circ} \mathrm{C}$ of pristine material were compared with isotherms of most interesting modified samples and presented in Figure 1. All of the isotherms exhibits type I and IV behavior according to IUPAC. Type I indicates presence of micropores, due to fast adsorption of $\mathrm{N}_{2}$ at low $\mathrm{P} /$ $\mathrm{P}_{0}$. On the other hand, type IV indicates presence of mesopores, due to hysteresis phenomenon in the range 0.4-0.8 of $\mathrm{P} / \mathrm{P}_{0}$.

Nitrogen sorption at $-196^{\circ} \mathrm{C}$ is used to calculate PSD for mesopores, using DFT theory. Distributions for three selected samples are presented in Figure 2.

Secondary activation significantly increases mesopore volume in the $2-5 \mathrm{~nm}$ range: from 0.11 to 0.15 and 0.24

Table 1. Textural properties of presented samples. The highest values were bolded

\begin{tabular}{|c|c|c|c|c|c|}
\hline \multirow{2}{*}{ Sample } & \multirow{2}{*}{$\mathrm{SSA}\left[\mathrm{m}^{2} / \mathrm{g}\right]$} & \multirow{2}{*}{$\mathrm{CO}_{2}$ uptake at $0{ }^{\circ} \mathrm{C}[\mathrm{mmol} / \mathrm{g}]$} & \multicolumn{3}{|c|}{ Pore volume $\left[\mathrm{cm}^{3} / \mathrm{g}\right]$} \\
\hline & & & total & micro & submicro \\
\hline 10CO_pristine & 1225 & 3.90 & 0.55 & 0.39 & 0.18 \\
\hline 10006001 & 1201 & 3.23 & 0.53 & 0.38 & 0.16 \\
\hline $10 \mathrm{CO} 6002$ & 1389 & 4.39 & 0.61 & 0.45 & 0.20 \\
\hline $10 \mathrm{CO} 600 \_3$ & 1401 & 3.90 & 0.69 & 0.41 & 0.18 \\
\hline 10CO_700_1 & 1268 & 3.67 & 0.57 & 0.42 & 0.17 \\
\hline $10 \mathrm{CO} 7002$ & 1546 & 4.54 & 0.69 & 0.48 & 0.25 \\
\hline $10 \mathrm{CO} 7003$ & 1612 & 3.88 & 0.78 & 0.46 & 0.17 \\
\hline $10 \mathrm{CO} 8001$ & 1394 & 4.26 & 0.63 & 0.47 & 0.21 \\
\hline $10 \mathrm{CO} 800 \_2$ & 1612 & 4.19 & 0.75 & 0.53 & 0.19 \\
\hline 10008003 & 1717 & 4.28 & 0.83 & 0.49 & 0.18 \\
\hline
\end{tabular}
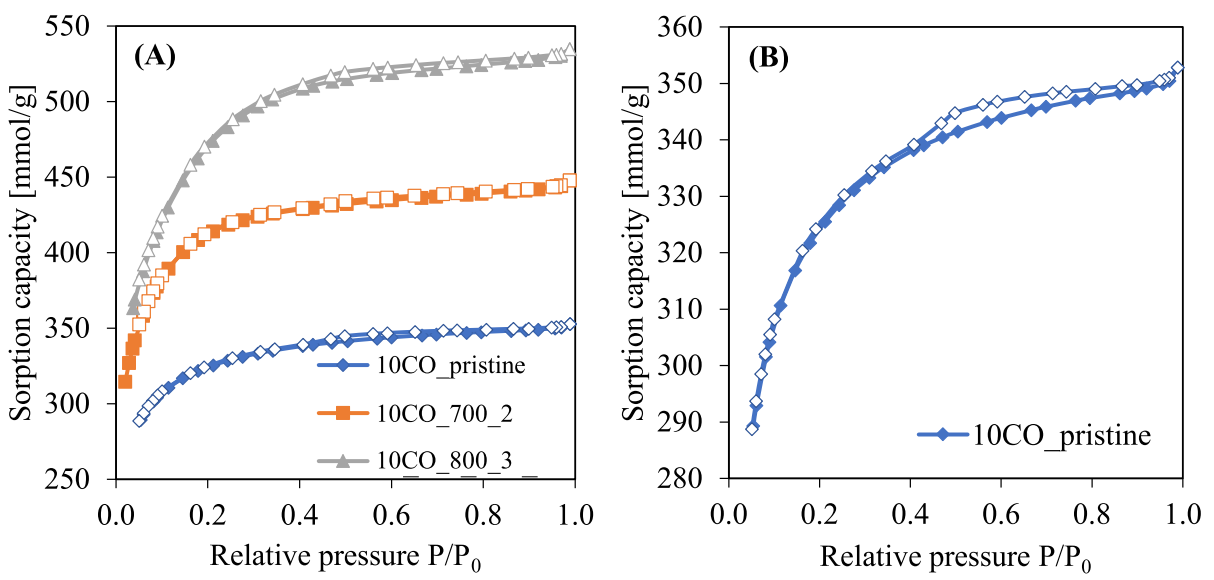

Figure 1. Nitrogen adsorption/desorption isotherms at $-196^{\circ} \mathrm{C}$ : (A) - shape comparison of three samples, (B) - isotherms for one sample with visible hysteresis phenomenon. Adsorption and desorption isotherms are presented by full and empty points respectively

As presented in Table 1, the most interesting samples are 10CO_700_2 and 10CO_800_3 with the highest $\mathrm{CO}_{2}$ sorption capacity and the highest specific surface area respectively. It may be seen that the highest carbon dioxide uptake does not correlate with the highest SSA, but do correlate with pores of diameter up to $0.8 \mathrm{~nm}$. Interestingly, the samples $10 \mathrm{CO}$ _pristine and 10CO_800_3 with similar submicropore volume of 18 $\mathrm{cm}^{3} / \mathrm{g}$ exhibit significant differences in $\mathrm{CO}_{2}$ uptakes, i.e. 3.90 and $4.28 \mathrm{mmol} / \mathrm{g}$ respectively. Most likely the discrepancy results from differences in SSA: 1225 and $1717 \mathrm{~m}^{2} / \mathrm{g}$ respectively. This indicates that $\mathrm{CO}_{2}$ uptake is a function of submicropore volume and SSA.

One can notice that for each activation temperature the specific surface area is increasing with increasing ratio of $\mathrm{K} / \mathrm{AC}$. The submicropore volume is highest for $\mathrm{K} / \mathrm{AC}=2$

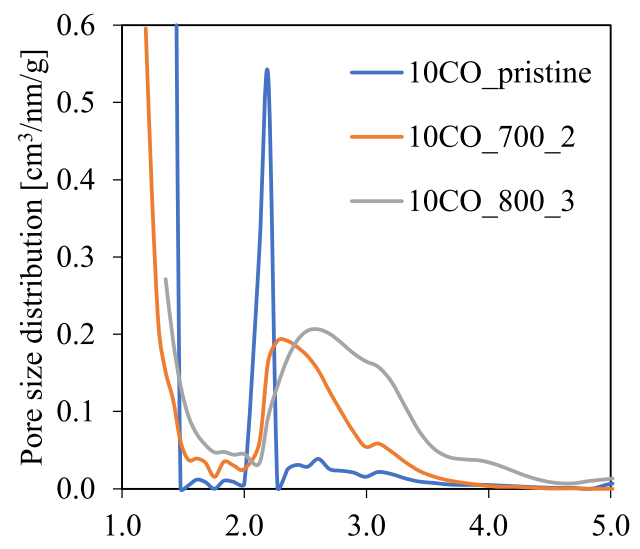

Figure 2. PSD calculated from nitrogen adsorption/desorption at $-196^{\circ} \mathrm{C}$ isotherms 
$\mathrm{cm}^{3} / \mathrm{g}$ for $10 \mathrm{CO}$ pristine, 10CO_700_2 and 10CO_800_3 respectively. The pore volume is proportional to the area under the curve in Figure 2. The mesopores are responsible for hysteresis phenomenon during nitrogen adsorption/desorption from Figure 1.

Basing on obtained data, some correlations were observed and presented in Figure $3 \mathrm{~A}$ and $3 \mathrm{~B}$. It is clear from Figure 3 that total and micropore volumes increase linearly with temperature of activation. The effect of K/ $\mathrm{AC}$ ratio is also visible. from pores in the range $0.8-1.0 \mathrm{~nm}$. Therefore one may expect good performance in $\mathrm{CO}_{2}$ sorption at pressure higher than 1 bar.

\section{SEM characterization}

Scanning electron microscopy was used to determine the structure of the activated carbon. Micrographs presented in figure 6 were taken using accelerating voltage of $5 \mathrm{kV}$ at $4000 \mathrm{x}$ magnification.
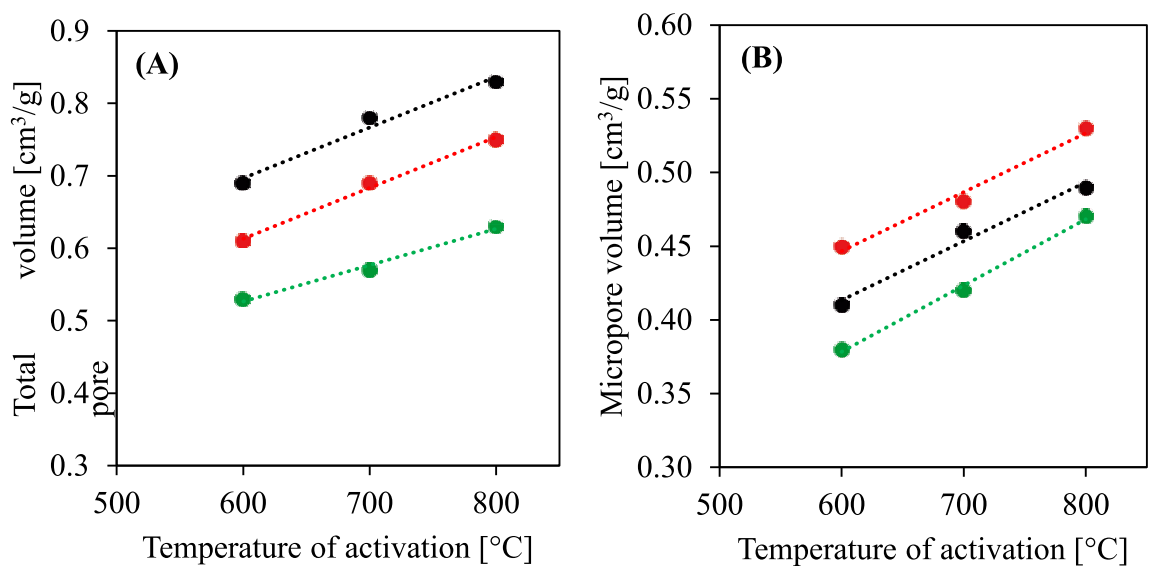

$\cdots \cdots \cdots \cdot \mathrm{K} / \mathrm{C}=1 \quad \cdots \cdots \cdots \cdot \mathrm{K} / \mathrm{C}=2 \quad \cdots \cdots \cdots \cdot \mathrm{K} / \mathrm{C}=3$

Figure 3. Correlations of total and micropore volumes with $\mathrm{K} / \mathrm{AC}$ ratio and activation temperature. Color of lines and points indicate different ratio $\mathrm{K} / \mathrm{AC}$

Figure 4 presents adsorption isotherms of carbon dioxide for three samples. Experiments were performed at $0^{\circ} \mathrm{C}$ and under pressure of up to 0.95 bar. The corresponding $\mathrm{CO}_{2}$ uptakes are presented in Table 1 .

According to literature data the most important pores responsible for high $\mathrm{CO}_{2}$ uptake are submicropores of size up to $0.8 \mathrm{~nm}$ at 1 bar. Figure 5 presents pore size distributions calculated with non-linear density functional theory (NLDFT) method. Clearly the secondary activation has an impact on the distributions. However, cumulative pore volume of submicropores up to $0.8 \mathrm{~nm}$ is the same for sample 10CO_pristine and 10CO_800_3, as presented in Table 1. Sample 10CO_700_2 has the highest submicropore volume in the range $0 . \overline{3}-0.8 \mathrm{~nm}$. However the sample 10CO_800_3 has prominent peak

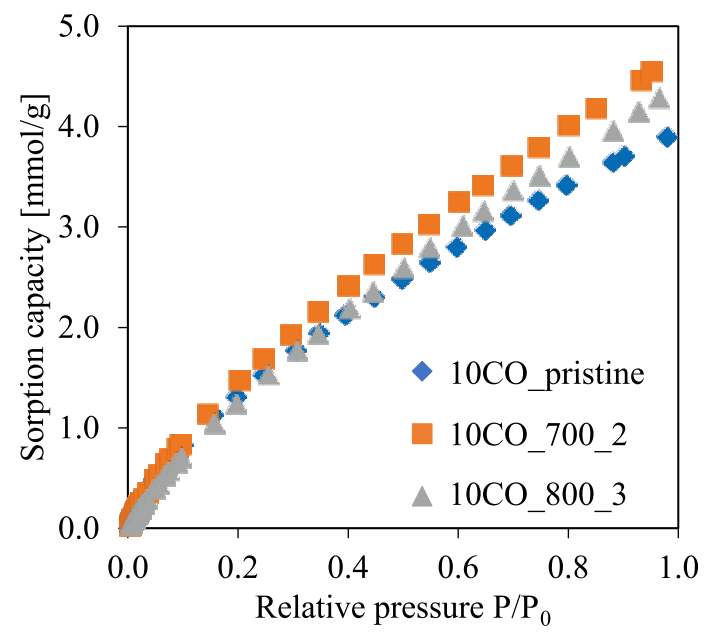

Figure 4. Carbon dioxide adsorption isotherms at $0^{\circ} \mathrm{C}$

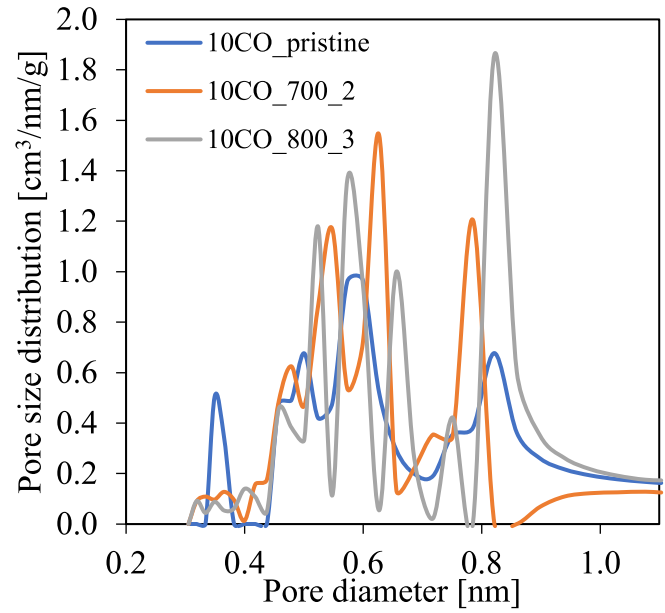

Figure 5. PSD calculated from $\mathrm{CO}_{2}$ adsorption/desorption at $0^{\circ} \mathrm{C}$

It is clearly visible that all samples contain narrow holes, which indicates its organic origin - commercial activated carbon 10CO was obtained from coconut shell. There were not observed any visual changes in morphology of secondary activated AC. This notion is fully consistent with other results. The changes in the materials induced by secondary activation occurs in nanometric scale and do not influence material in macroscale.

\section{EDS analysis}

To study the impact of structural changes on carbon dioxide sorption, removal of potassium was necessary. The presence of potassium compounds could influence the uptake, resulting in an overstated value. Therefore, 

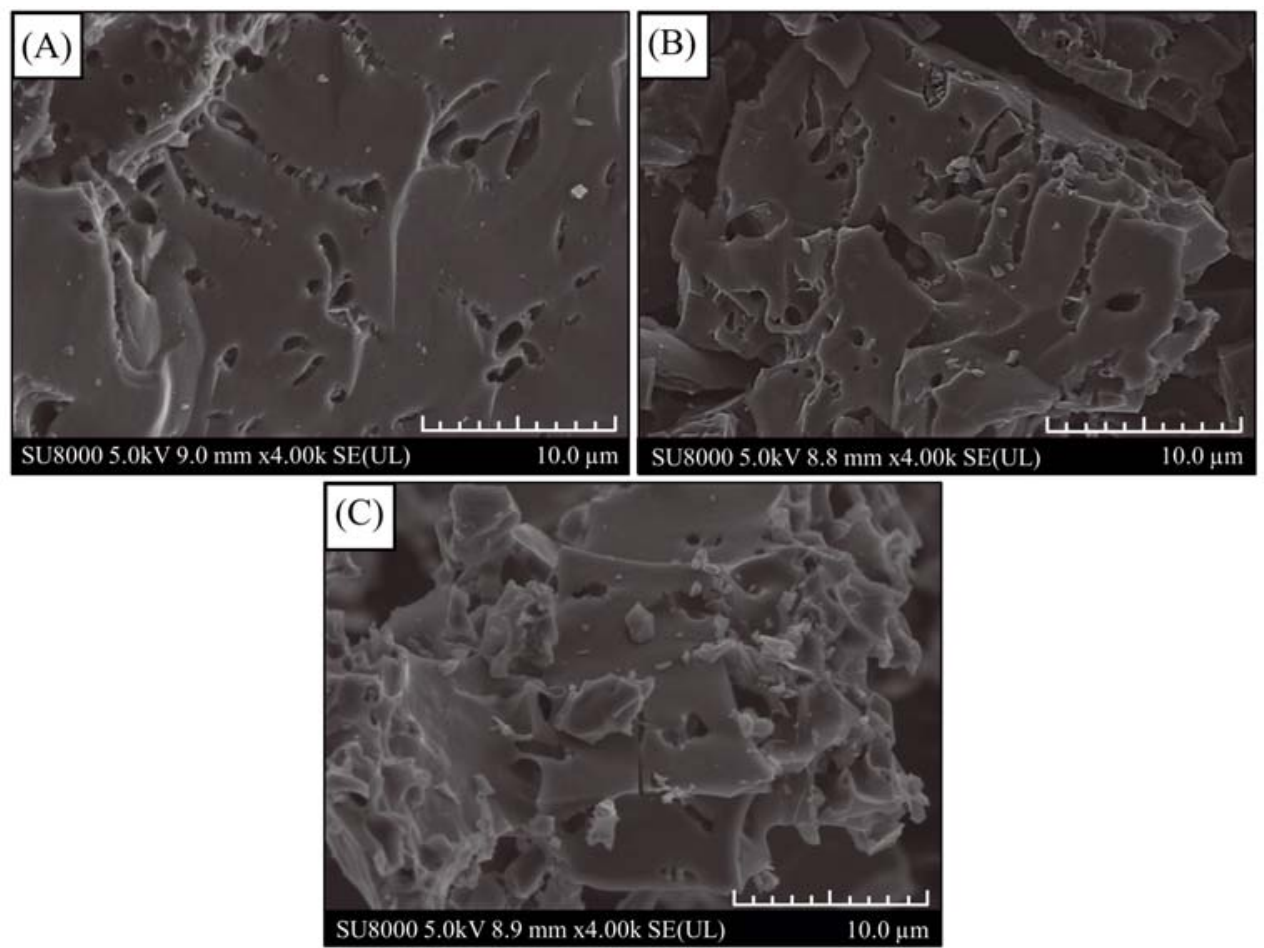

Figure 6. SEM micrographs of three samples: (A) - 10CO_pristine, (B) - 10CO_700_2, (C) - 10CO_800_3

EDS analysis was used to confirm elemental composition of the sample after secondary activation. Results of this analysis are presented in Table 2. Fig. 7 shows potassium $\mathrm{K}_{\alpha}$ and $\mathrm{K}_{\beta} \mathrm{X}$-ray transitions used to evaluate concentration. The $\mathrm{HCl}$ treatment followed by washing with distillated water significantly reduces potassium content in pristine sample, which is 1.45 at. $\%$ prior washing out ${ }^{6}$. The same process of washing out potassium with $\mathrm{HCl}$ led to different potassium content. The highest content is in the pristine sample. This indicates that potassium is trapped in the structure of AC. After modification of the porous structure by secondary activation with $\mathrm{KOH}$, the potassium can be washed out in higher degree.

Table 2. EDS results of potassium removal

\begin{tabular}{|l|c|}
\hline Sample & Potassium content [at.\%] \\
\hline $10 C O \_$pristine & 0.7 \\
\hline $10 C 0 \_700 \_2$ & 0.1 \\
\hline $10 C 0 \_800 \_3$ & 0.2 \\
\hline
\end{tabular}

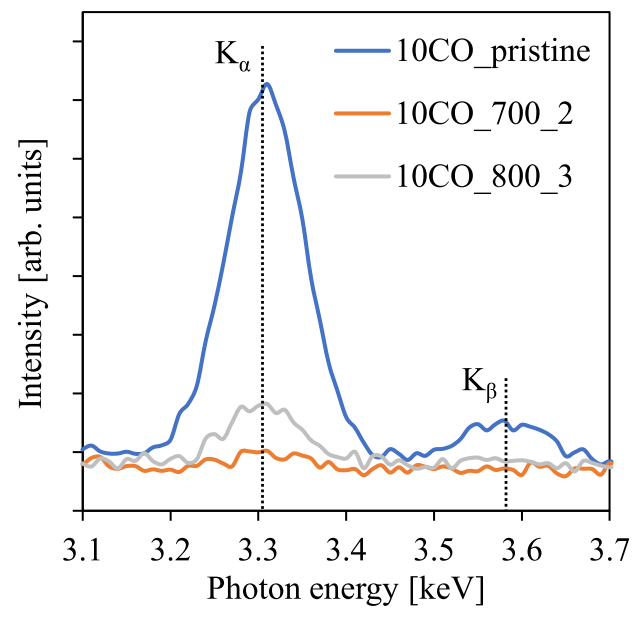

Figure 7. Potassium EDS spectra of three samples. $\mathrm{K}_{\alpha}$ and $\mathrm{K}_{\beta}$ transitions of potassium were labeled at particular peaks
Nevertheless, some amount of potassium remained in samples. The higher potassium content in the 10C_800_3 may result from deeper penetration of graphitic layers by potassium ions thereby preventing its complete removal.

\section{XPS analysis}

X-ray photoelectron spectroscopy analysis provided information about changes in chemical composition of the material's surface. XPS also confirmed the presence of potassium in the pristine sample with two distinctive peaks overlapped with the $\mathrm{C}$ 1s spectrum. The EDS quantitative results enabled us to improve the model used in spectrum deconvolution. Table 3 presents atomic concentrations of carbon, oxygen and potassium in the chosen samples. It was assumed that potassium would be present in the form of potassium carbonate, therefore contribution of this compound was taken into account, while calculating area, either of $\mathrm{C} 1 \mathrm{~s}$ and $\mathrm{O} 1 \mathrm{~s}$ spectra.

It was observed that concentration of carbon was higher for modified samples than in pristine material. It could be caused by thermal desorption of some functional groups, made of carbon and oxygen ${ }^{37}$. Interestingly concentrations of potassium obtained with XPS and EDS in samples 10CO_700_2 and 10CO_800_3 are apparently not in agreement. However, with XPS the depth of analysis is roughly $1 \mathrm{~nm}$, while in case of EDS it is roughly 1000 $\mathrm{nm}$. This suggests that at higher temperature potassium is being incorporated deeper in carbon and thus its signal is attenuated in XPS analysis. This is also in line with

Table 3. Atomic concentrations of two main elements in the sample

\begin{tabular}{|l|c|c|c|}
\hline \multirow{2}{*}{1} & \multicolumn{3}{|c|}{ Atomic concentration [\%] } \\
\cline { 2 - 4 } & $\mathrm{C}$ & $\mathrm{O}$ & $\mathrm{K}$ \\
\hline 10CO_pristine & 90.8 & 6.6 & 2.6 \\
\hline 10CO_700_2 & 93.2 & 5.2 & 1.6 \\
\hline 10CO_800_3 & 94.8 & 4.6 & 0.6 \\
\hline
\end{tabular}


previous notion that high concentration of potassium in sample 10CO_800_3 as measured with EDS results from deep incorporation mechanism.

Deconvolution of $\mathrm{C}$ 1s spectrum was performed for each sample, providing data about contribution of each particular constituent. The following groups originating from the carbon signal were identified ${ }^{\mathbf{6}}$ : $\mathrm{C} \mathrm{sp}^{2} 284.6$ $\pm 0.3 \mathrm{eV}, \mathrm{C}-\mathrm{O} 286.1 \pm 0.3 \mathrm{eV}$, keto-enolic $286.4 \pm 0.3 \mathrm{eV}$, $\mathrm{C}=\mathrm{O} 287.6 \pm 0.3 \mathrm{eV}, \mathrm{COOH} 289.1 \pm 0.3 \mathrm{eV}$, carbonate $290.6 \pm 0.3 \mathrm{eV}$, satellite $292.15 \pm 2.15$ (determined experimentally), $\mathrm{K} 2 \mathrm{p}_{3 / 2} 292.5 \pm 0.2 \mathrm{eV}$ and $\mathrm{K} 2 \mathrm{p}_{1 / 2}$ $+2.77 \mathrm{eV}$. Table 4 and Figure 8 present contributions of those constituents and deconvolution of $\mathrm{C} 1 \mathrm{~s}$ spectrum for the pristine sample, respectively.

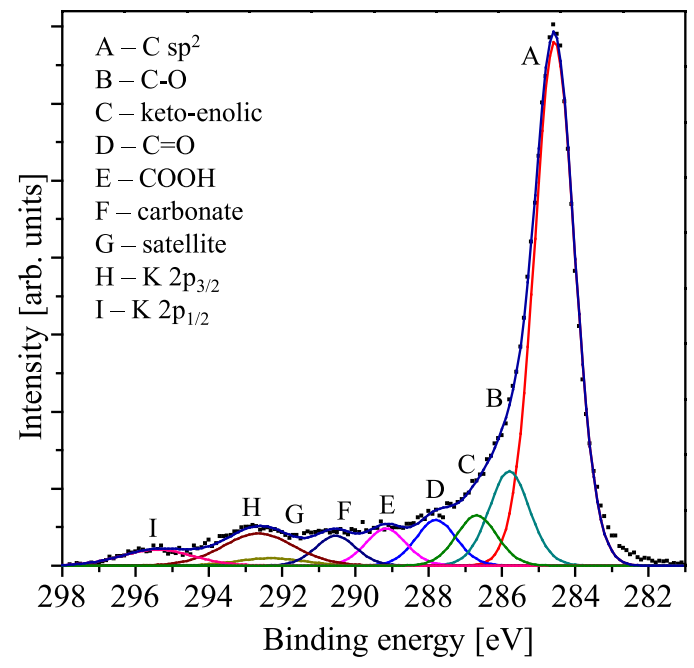

Figure 8. Deconvolution of $\mathrm{C} 1 \mathrm{~s}$ spectrum

The provided data suggests partial removal of potassium and the $\mathrm{COOH}$ group, due to reducing their constituents. Potassium (already present and added as activating agent) was removed via hydrochloric acid treatment after the activation step. Carboxylic groups are decomposed with high temperature treatment, due to the lowest temperature $\left(100-250^{\circ} \mathrm{C}\right)$ of decomposition ${ }^{37}$. Nevertheless changes in the other components are neglible, therefore one may conclude that secondary activation has not changed the chemistry of the surface. Therefore, the chemistry of the surface cannot be responsible for observed changes in $\mathrm{CO}_{2}$ uptake. This is an important conclusion because observed changes in $\mathrm{CO}_{2}$ uptake must then result from changes in pore size distributions and SSA.

\section{XRD analysis}

Figure 9 presents XRD spectra of most interesting samples. There are visible two broad XRD reflections. The (002) reflection originates from graphitic layers. Shifting of this reflection toward lower angles indicates increase of distance between crystallographic planes. Such shift is visible in case of $10 \mathrm{CO} \_700 \_2$. It is expected that incorporation of potassium cations between graphitic layers will result in distance increase. In case

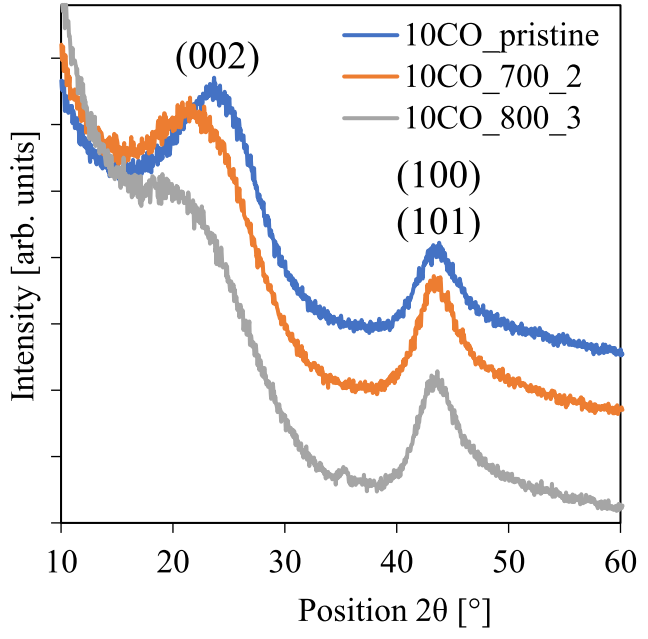

Figure 9. Diffraction patterns of samples 10CO_pristine, 10CO_700_2 and 10CO_800_3

of 10CO_800_3 sample the shift is the highest and the intensity of (002) reflection is significantly lower compared to other samples. The highest shift correlates with the high concentration of potassium (Table 2). The pristine sample has the highest potassium content, but the lowest shift. Therefore, in case of pristine sample the potassium compound must be in the form of agglomerations, while in case of other samples in the form of intercalates.

The intensity of other reflex is comparable. Lower intensity may be result of transformation of material into amorphous form. The diffraction phenomena occurs only on ordered materials. If the graphitic layers will be distorted in such a way that they will be not parallel then one may expect that the diffraction will vanish resulting in lower intensity. The low crystallinity of sample 10CO_800_3 is in line with other result showing deep penetration of this material with potassium cations.

\section{CONCLUSIONS}

Through secondary activation of AC the higher SSA and pore volume may be obtained. Activation at the highest temperature of $800^{\circ} \mathrm{C}$ with the highest ratio of $\mathrm{K} / \mathrm{AC}$ $=3$ provides the highest SSA $\left(1717 \mathrm{~m}^{2} / \mathrm{g}, 40 \%\right.$ increase $)$. Lower temperature $\left(700^{\circ} \mathrm{C}\right)$ and lower ratio $\mathrm{K} / \mathrm{AC}=$ 2 resulted in highest $\mathrm{CO}_{2}$ uptake $\left(4.54 \mathrm{mmol} / \mathrm{g}\right.$ at $0^{\circ} \mathrm{C}$, 1 bar, $16 \%$ increase), due to increase of submicropores volume (from $0.18 \mathrm{~cm}^{3} / \mathrm{g}$ to $0.25 \mathrm{~cm}^{3} / \mathrm{g}, 39 \%$ increase).

XPS measurement clearly indicates that the chemistry of the surface has not changed after second activation. Therefore the observed changes in $\mathrm{CO}_{2}$ uptake must result solely from changes in pore size distribution and SSA. The highest $\mathrm{CO}_{2}$ uptake correlates with the highest volume of submicropores. However, samples with the same volume of submicropores exhibit differences in $\mathrm{CO}_{2}$ uptake, due to the differences in SSA. High temperature treatment at $800^{\circ} \mathrm{C}$ resulted in slight decrease of $\mathrm{COOH}$ groups over AC surface and deeper incorporation of

Table 4. Constituents originating from $\mathrm{C}$ 1s signal

\begin{tabular}{|l|c|c|c|c|c|c|}
\hline Sample & $\mathrm{C} \mathrm{sp}^{2}$ & $\mathrm{C}-\mathrm{O}$ & Keto-enolic & $\mathrm{C}=\mathrm{O}$ & $\mathrm{COOH}$ & $\mathrm{Carbonate}$ \\
\hline 10CO_pristine & 0.68 & 0.12 & 0.05 & 0.06 & 0.05 & 0.04 \\
\hline 10CO_700_2 & 0.67 & 0.13 & 0.07 & 0.06 & 0.05 \\
\hline 10CO_800_3 & 0.73 & 0.13 & 0.07 & 0.04 & 0.02 & 0.02 \\
\hline
\end{tabular}


potassium ions in carbonaceous material as confirmed by XPS, EDS and XRD data.

\section{LITERATURE CITED}

1. NASA's Goddard Institute for Space Studies. Retrieved June 29, 2018, from https://climate.nasa.gov/vital-signs/global-temperature/

2. Pfeffer, W.T., Harper, J.T. \& O’Neel, S. (2008). Kinematic constraints on glacier contributions to 21 st-century sea-level rise. Science 321 1340-1343. DOI: 10.1126/science.1159099.

3. Wallace, J.M., \& Hobbs, P.V. (2006). Atmospheric Science An Introductory Survey (2nd ed.). Seattle, USA: Elsevier

4. Etheridge, D.M., Steele, L.P., Langenfelds, R.L., Francey, R.J., Barnola, J.M. \& Morgan, V.I. (1996). Natural and anthropogenic changes in atmospheric $\mathrm{CO}_{2}$ over the last 1000 years from air in Antarctic and firn. J. Geophys. Res.-Atmos. 101 4115-4128. DOI: https://doi.org/10.1029/95JD03410.

5. Tans, P. \& Keeling, R. Trends in Atmospheric Carbon Dioxide. Retrieved June 29, 2018, from https://www.esrl.noaa. gov/gmd/ccgg/trends/data.html

6. Gęsikiewicz-Puchalska, A., Zgrzebnicki, M., Michalkiewicz, B., Narkiewicz, U., Morawski, A.W. \& Wrobel, R.J. (2017). Improvement of $\mathrm{CO}_{2}$ uptake of activated carbons by treatment with mineral acids. Chem. Eng. J. 309 159-171. DOI: https://doi.org/10.1016/j.cej.2016.10.005.

7. Harald, D., Frisvold, P., Gunningham, N., Jaccard, M., Langhelle, O., Meadowcroft, J., Praetorius, B., Scrase, I., Sharp, J., Sinclair, D., Stephens, J.C., Tjernshaugen, A., Vergragt, P.J., von Stechow, C. \& Watson, J. (2009). Caching the Carbon, the Politics and Policy of Carbon Capture and Storage. Chelteham: Edward Elgar Publishing Limited.

8. Młodzik, J., Sreńscek-Nazzal, J., Narkiewicz, U., Morawski, A.W., Wróbel, R.J. \& Michalkiewicz, B. (2016). Activated Carbons from Molasses as $\mathrm{CO}_{2}$ Sorbents. Acta Phys. Pol. A. 129, 402-405. DOI: 10.12693/APhysPolA.129.402.

9. Sreńscek-Nazzal, J., Narkiewicz, U., Morawski, A.W., Wróbel, R., Gęsikiewicz-Puchalska, A. \& Michalkiewicz, B. (2016). Modification of Commercial Activated Carbons for $\mathrm{CO}_{2}$ Adsorption. Acta Phys. Pol. A. 129, 394-401. DOI: 10.12693/ APhysPolA.129.394.

10. Glonek, K., Sreńscek-Nazzal, J., Narkiewicz, U., Morawski, A.W., Wróbel, R.J. \& Michalkiewicz, B. (2016). Preparation of Activated Carbon from Beet Molasses and $\mathrm{TiO}_{2}$ as the Adsorption of $\mathrm{CO}_{2}$. Acta Phys. Pol. A. 129 158-161. DOI: 10.12693/APhysPolA.129.158.

11. Kapica-Kozar, J., Kusiak-Nejman, E., Wanag, A., Kowalczyk, Ł., Wrobel, R.J., Mozia, S. \& Morawski, A.W. (2015). Alkali-treated titanium dioxide as adsorbent for $\mathrm{CO}_{2}$ capture from air. Micropor. Mesopor. Mat. 202, 241-249. DOI: https:// doi.org/10.1016/j.micromeso.2014.10.013.

12. Kapica-Kozar, J., Piróg, E., Wrobel, R.J., Mozia, S., Kusiak-Nejman, E., Morawski, A.W., Narkiewicz, U. \& Michalkiewicz, B. (2016). $\mathrm{TiO}_{2} /$ titanate composite nanorod obtained from various alkali solutions as $\mathrm{CO}_{2}$ sorbents from exhaust gases. Micropor. Mesopor. Mat. 231, 117-127. DOI: https://doi. org/10.1016/j.micromeso.2016.05.024.

13. Kapica-Kozar, J., Piróg, E., Kusiak-Nejman, E., Wrobel, R.J., Gęsikiewicz-Puchalska, A., Morawski, A.W., Narkiewicz, U. \& Michalkiewicz, B. (2017). Titanium dioxide modified with various amines used as sorbents of carbon dioxide. New J. Chem. 41(4) 1549-1557. DOI: 10.1039/C6NJ02808J.

14. Kapica-Kozar, J., Michalkiewicz, B., Wrobel, R.J., Mozia, S., Piróg, E., Kusiak-Nejman, E., Serafin, J., Morawski A.W. \& Narkiewicz, U. (2017). Adsorption of carbon dioxide on TEPAmodified $\mathrm{TiO}_{2}$ /titanate composite nanorods. 41, 7870-7885. DOI: $10.1039 / \mathrm{C} 7 \mathrm{NJ} 01549 \mathrm{~F}$.

15. Figueiredo, J.L. (2013). Functionalization of porous carbons for catalytic applications. J. Mater. Chem. A. 19351-9364. DOI: $10.1039 / \mathrm{C} 3 \mathrm{TA} 10876 \mathrm{G}$
16. Serafin, J., Narkiewicz, U., Morawski, A.W., Wrobel, R.J. \& Michalkiewicz, B. (2017). Highly microporous activated carbons from biomass for $\mathrm{CO}_{2}$ capture and effective micropores

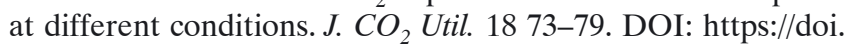
org/10.1016/j.jcou.2017.01.006.

17. Danish, M. \& Ahmad, T. (2018). A review on utilization of wood biomass as a sustainable precursor for activated carbon production and application. Renew. Sust. Energ. Rev. 87 1-21. DOI: https://doi.org/10.1016/j.rser.2018.02.003.

18. Wiśniewska, M., Nowicki, P., Nosal-Wiercińska, A., Pietrzak, R., Szewczuk-Karpisz, K., Ostolska, I. \& Sternik, D. (2017). Adsorption of poly(acrylic acid) on the surface of microporous activated carbon obtained from cherry stones. Colloid Surface A. 514, 137-145. DOI: https://doi.org/10.1016/j. colsurfa.2016.11.053.

19. Popa, N. \& Visa, M. (2017). The synthesis, activation and characterization of charcoal powder for the removal of methylene blue and cadmium from wastewater. Adv. Powder Technol. 28(8) 1866-1876. DOI: https://doi.org/10.1016/j.apt.2017.04.014.

20. Qu, S., Wan, J., Dai, C., Jin, T. \& Ma, F. (2018). Promising as high-performance supercapacitor electrode materials porous carbons derived from biological lotus leaf. J. Alloy Compd. 751 107-116. DOI: https://doi.org/10.1016/j.jallcom.2018.04.123.

21. Górka, J. \& Jaroniec, M. (2011). Hierarchically porous phenolic resin based carbons obtained by block copolymer colloidal silica templating and post synthesis activation with carbon dioxide and water vapor. Carbon 49 154-160. DOI: https://doi.org/10.1016/j.carbon.2010.08.055.

22. Meng, L.Y. \& Park, S.J. (2014). Effect of $\mathrm{ZnCl}_{2}$ activation on $\mathrm{CO}_{2}$ adsorption of $\mathrm{N}$-doped nanoporous carbons from polypyrrole. J. Solid State Chem. 281 90-94. DOI: https://doi. org/10.1016/j.jssc.2014.06.005.

23. Sreńscek-Nazzal, J., Narkiewicz, U., Morawski, A.W., Wrobel, R.J. \& Michalkiewicz, B. (2016). The increase of the microporosity and $\mathrm{CO}_{2}$ adsorption capacity of the commercial activated carbon CWZ-22 by KOH treatment. In R.S. Dariani (Ed), Microporous and mesoporous materials (2-19). Rijeka: InTech. DOI: 10.5772/63672.

24. Arami-Niya, A., Daud, W.M.A.W. \& Mjalli, F.S. (2011). Comparative study of the textural characteristics of oil palm shell activated carbon produced by chemical and physical activation for methane adsorption. Chem. Eng. Res. Des. 89(6) 657-664. DOI: https://doi.org/10.1016/j.cherd.2010.10.003.

25. Mitra, S. (2016). U.S. Patent No. 9938152. Washington, D.C.: U.S. Patent and Trademark Office.

26. Guskos, N., Typek, J., Maryniak, M., Narkiewicz, U., Kucharewicz, I. \& Wróbel, R. (2005). FMR study of agglomerated nanoparticles in a Fe3C/C system. Mater. Sci. Poland 23(4) 102-106.

27. Wrobel, R.J., Hełminiak, A., Arabczyk, W. \& Narkiewicz, U. (2014). Studies on the Kinetics of Carbon Deposit Formation on Nanocrystalline Iron Stabilized with Structural Promoters. J. Phys. Chem. C. 118(28) 15434-15439. DOI: 10.1021/jp4108377.

28. Yu, K., Li, J., Qi, H. \& Liang, Ce. (2018). High-capacity activated carbon anode material for lithium-ion batteries prepared from rice husk by a facile method. Diam. Relat. Mater. 86 139-145. DOI: https://doi.org/10.1016/j.diamond.2018.04.019.

29. Młodzik, J., Wróblewska, A., Makuch, E., Wróbel, R.J. \& Michalkiewicz, B. (2016). Fe/EuroPh catalyst for limonene oxidation to 1,2-epoxylimonene, its diol, carveol, carvone and perillyl alcohol. Catal. Today 268 111-120. DOI: https://doi. org/10.1016/j.cattod.2015.11.010.

30. Glonek, K., Wróblewska, A., Makuch, E., Ulejczyk, B., Krawczyk, K., Wróbel, R.J., Koren, Z.C. \& Michalkiewicz, B. (2017). Oxidation of limonene using activated carbon modified in dielectric barrier discharge plasma. Appl. Surf. Sci. 420 873-881. DOI: https://doi.org/10.1016/j.apsusc.2017.05.136.

31. Pełech, R., Milchert, E. \& Wróbel, R. (2006). Adsorption dynamics of chlorinated hydrocarbons from multi-component 
aqueous solution onto activated carbon. J. Hazard. Mater. 137 1479-1487. DOI: https://doi.org/10.1016/j.jhazmat.2006.04.023.

32. Zgrzebnicki, M., Krauze, N., Gęsikiewicz-Puchalska, A., Kapica-Kozar, J., Piróg, E., Jędrzejewska, A., Michalkiewicz, B., Narkiewicz, U., Morawski A.W. \& Wrobel, R.J. (2017). Impact on $\mathrm{CO}_{2}$ Uptake of MWCNT after Acid Treatment Study. J. Nanomater. 2017. DOI: https://doi.org/10.1155/2017/7359591.

33. Tiwari, D., Bhunia, H. \& Bajpai, P.K. (2018). Adsorption of $\mathrm{CO}_{2}$ on $\mathrm{KOH}$ activated, N-enriched carbon derived from urea formaldehyde resin: kinetics, isotherm and thermodynamic studies. Appl. Surf. Science 439 760-771. DOI: https:// doi.org/10.1016/j.apsusc.2017.12.203.

34. Ludwinowicz, J. \& Jaroniec, M. (2015). Effect of activation agents on the development of microporosity in polymeric-based carbon for $\mathrm{CO}_{2}$ adsorption. Carbon 94 673-679. DOI: https:// doi.org/10.1016/j.carbon.2015.07.052.

35. Presser, V., McDonough, J., Yeon, S.H. \& Gogotsi, Y. (2011). Effect of pore size on carbon dioxide sorption by carbide derived carbon. Energy Environ. Sci. 4 3059-3066. DOI: 10.1039/C1EE01176F.

36. Wrobel, R.J. \& Becker, S. (2010). Carbon and sulphur on $\mathrm{Pd}(111)$ and $\mathrm{Pt}(111)$ : Experimental problems during cleaning of the substrates and impact of sulphur on the redox properties of $\mathrm{CeO}_{\mathrm{x}}$ in the $\mathrm{CeO}_{\mathrm{x}} / \mathrm{Pt}(111)$ system. Vacuum 84(11) 1258-1265. DOI: https://doi.org/10.1016/j.vacuum.2010.01.056.

37. Figueiredo, J.L., Pereira, M.F.R., Freitas, M.M.A. \& Orfao, J.J.M. (1999). Modification of the surface chemistry of activated carbons. Carbon 37 1379-1389. DOI: https://doi. org/10.1016/S0008-6223(98)00333-9. 